\title{
Impacto da Governança das Plataformas digitais na criação e apropriação de valor em Ecossistemas de negócio
}

\author{
Sergio Leal, Bruna Diirr \\ ${ }^{1}$ Programa de Pós-Graduação em Informática da UNIRIO \\ sergio.lealdedu.unirio.br ${ }^{1}$, bruna.diirrduniriotec.br ${ }^{1}$
}

\begin{abstract}
In the last decade, digital platforms have gained importance in the orchestration of interorganizational relations, becoming control points in different business ecosystems. This can lead to conflicts between Platform Leaders and other participants in the search for opportunities for creating and appropriating value. In this work, the Governance of digital Platforms is investigated from the perspective of Complementors and seek to create mechanisms that allow to predict how the Leader's control over the Platform can affect the creation and appropriation of value in the Ecosystem. In the end, an artifact that supports both researchers and practitioners in making these predictions is proposed.
\end{abstract}

\begin{abstract}
Resumo. Na última década, as Plataformas digitais ganharam importância na orquestração das relações interorganizacionais, tornando-se pontos de controle em diversos Ecossistemas de negócio. Isso pode gerar conflitos entre os Líderes das Plataformas e outros participantes na busca de oportunidades para criação e apropriação de valor. Nesse trabalho, a Governança das Plataformas digitais é investigada pela perspectiva dos Complementors e busca-se criar mecanismos que permitam prognosticar como o controle do Líder sobre a Plataforma pode afetar a criação e apropriação de valor no Ecossistema. Ao final, será proposto um artefato que apoie tanto pesquisadores quanto praticantes na realização desses prognósticos.
\end{abstract}

\section{Introdução}

Empresas que desenvolvem aplicativos móveis encontram barreiras para atingir seu públicoalvo, pois os principais canais de acesso a ele são App Store (iOS) ou Play Store (Android). Isso cria um mecanismo que Apple e Google utilizam para controlar qual empresa ou produto pode ter acesso aos consumidores, sob que circunstância e a qual custo [Lovejoy 2021]. Dessa maneira, as Plataformas Digitais, i.e., que oferecem um núcleo estável para organizações terceiras criarem complementos capazes de adicionar-lhes novas funcionalidades, e operam como um hub em um mercado multilateral, mediando a interação entre diversas partes interessadas [de Reuver et al. 2018], passaram a atuar como um Gargalo, i.e., componentes críticos cujo desempenho, custos e escassez restringem a proposição de valor de um Ecossistema de Negócio, i.e., formados por grande número de participantes, levemente interconectados, que dependem uns dos outros para sua eficácia e sobrevivência mútuas[Peltoniemi and Vuori 2004]. O impacto dessa situação pode ser exemplificado com a Coalition for App Fairness, criada por empresas de desenvolvimento mobile que busca a liberdade de escolha dos consumidores e igualdade de condições de competição[for App Fairness 2021]. 
O presente estudo investiga os efeitos do posicionamento das Plataformas Digitais como Gargalos nos Ecossistemas de Negócios. Nesse contexto, os Líderes das Plataformas, i.e. organização provedora do núcleo da plataforma[Saarikko 2016], construíram um modelo onde seus serviços influenciam múltiplos aspectos dos Ecossistemas de Negócio permitindo controlar o fluxo de criação e apropriação de valor por parte dos participantes. Na literatura, o assunto de criação e apropriação de valor desperta interesse de pesquisadores, uma vez que a questão sobre como o valor é distribuído entre os participantes de um Ecossistema, i.e., quem captura qual parcela do valor, permanece sem resposta[Hein et al. 2019]. Além disso, um Mapeamento Sistemático da Literatura (MSL), ainda não publicado, executado pelos autores, indicou a existência de poucos estudos relacionando a Governança das Plataformas Digitais e o impacto sobre a criação e apropriação de valor nos Ecossistemas de Negócio. Na Indústria existe múltiplos casos de conflito na criação e apropriação de valor nas Plataformas Digitais como o do XCloud da Microsoft e o Stadia do Google - produtos que operam como hub de jogos, onde o usuário pode baixar jogos da mesma maneira que faz num console[Statt 2021], e a Apple bloqueou essas ofertas na App Store do iOS [Statt 2021]. Se pudessem prognosticar essas situações, as empresas poderiam redirecionar seus investimentos?

\section{Apresentação do problema}

Esse trabalho visa analisar como a Governança da Plataforma Digital pode afetar a criação e apropriação de Valor e, consequentemente, incentivar ou desencorajar o engajamento de participantes de um Ecossistema de Negócio. A questão de pesquisa é especificada como: "Como o participante de um Ecossistema de negócio pode avaliar o poder do Líder da Plataforma digital em manipular a Governança e controlar a criação e apropriação de valor num Ecossistema beneficiando determinados grupos?”. Além disso, a seguinte hipótese foi criada: "Se um Ecossistema de negócios depende fortemente de uma Plataforma digital onde o Líder pode alterar qualquer aspecto da Governança de forma unilateral, então o risco de manipular a criação e apropriação de valor direcionando os maiores benefícios é alto."

\section{Projeto da pesquisa}

Deseja-se contribuir para a literatura estudando o controle e a hegemonia de um grupo sobre outro à luz da teoria dos Boundary objects, i.e., interfaces padronizadas entre diferentes mundos sociais que possibilitam alcançar objetivos mútuos[Star and Griesemer 1989]. Se em um primeiro momento eles parecem neutros e apolíticos, isso não é verdadeiro, já que podem concretizar propósitos de criação e manutenção da hegemonia política de um grupo sobre outros[Star and Griesemer 1989]. O estudo atual analisa como os Gargalos de um Ecossistema de Negócio e, mais especificamente, as Plataformas Digitais podem ser vistas como Boundary objects e assim analisar com mais profundidade seu papel para a dominação dos Líderes das Plataformas sobre os outros participantes do Ecossistema.

A proposta é baseada em uma análise de gaps, técnica que permite identificar as diferenças entre o estado atual e aquele que se pretende alcançar, para se aplicada do ponto de vista dos usuários da Plataforma [Smartsheet 2021]. Desenvolveremos um modelo de uma arquitetura de referência para Plataformas Digitais onde todos os mecanismos de controle do processo de criação e apropriação de valor serão removidos. A OpenDPA 
(Open Digital Platform Architecture) servirá como modelo de comparação com as Plataformas atuais objetivando determinar o quanto elas diferem entre si e, por consequência, o nível de controle do Líder sobre ela ("nível de abertura da plataforma").

O modelo não será aplicável às Plataformas transacionais, i.e., que fazem o match entre vários lados do mercado, mas apenas às Plataformas de inovação, i.e., fornecem uma estrutura de tecnologia comum sobre a qual outros podem construir (de Reuver et al., 2018). A OpenDPA terá características como modularidade, para que subsistemas inteiros possam ser substituídos pelos usuários, e ser baseada em APIs, para que o usuário escolha a implementação desejada. Assim, qualquer pessoa pode escolher usar uma "Loja de Aplicativos" ou meio de pagamento alternativos, ou instalar uma implementação da API de Realidade Aumentada mais adequada às suas necessidades. O projeto de construção da solução foi dividido em seis fases (Fig. 1). A Documentação "AS IS" visa a análise da situação atual das principais Plataformas transacionais e de inovação para identificar os principais Gargalos. Na Análise de Oportunidades de Melhoria, cada um dos elementos destacados será analisado para identificar as melhores opções que minimizem seu impacto sobre o Ecossistema de negócios. Na Composição da Solução, as descobertas da fase 2 ajudarão a compor a OpenDPA, visando desenhar uma arquitetura sem as restrições identificadas nos desenhos iniciais. Na Análise de Gaps, será criado um modelo analítico para comparar uma Plataforma digital com a OpenDPA, gerando um índice que reflete o nível de abertura da Plataforma (analisados 3 aspectos: Potencial de Generatividade, Assimetria de Informações, e Poder de alterar unilateralmente a dinâmica da Plataforma). $\mathrm{O}$ Desenvolvimento de indicadores permitirá a construção de métodos de cálculo de cada um dos indicadores. Na Construção de instrumento, um artefato, a ser elaborado, permitirá o cálculo do nível de abertura da plataforma. Plataformas abertas não impõem restrições na participação de seu desenvolvimento, comercialização ou utilização ou, quando isso acontece (ex.: requisitos de conformidade técnica ou de pagamento de taxas de licenciamento), são razoáveis e não discriminatórias[Parker et al. 2016].

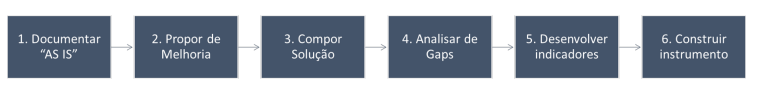

Figura 1. Figura 1: Fases do Projeto

Para prognosticar a evolução da criação e apropriação de valor, os Líderes das Plataforma podem desenvolver métricas que visam problemas de monetização. Alguns exemplos de indicadores: Quais usuários estão aproveitando o maior valor das atividades da plataforma? Quais usuários precisam ser subsidiados para garantir sua participação contínua? Qual fração da criação de valor liberada pela plataforma está ocorrendo na e fora da plataforma? Quanto valor adicional pode ser criado por meio de serviços como curadoria aprimorada? Quais grupos fora da plataforma podem achar valor no acesso a usuários específicos da plataforma?[Parker et al. 2016].

\section{Projeto de avaliação}

Um estudo de caso será conduzido utilizando uma Plataforma digital de inovação de pequeno porte. Esta plataforma é usada em Ecossistema de Negócio na área de Educação e Pesquisa ainda na sua fase inicial. Os principais atores que se integram à Plataforma são (i) o Líder, controla a oferta de serviços e (ii) Provedores externos de aplicações que já 
publicaram, tentaram, ou desistiram de publicar complementos na Plataforma. Os pesquisadores têm acesso a todos esses atores, o que possibilita implementar a solução proposta e avaliar a aplicabilidade dos resultados gerados.

No início do estudo, representantes dos diversos grupos serão convidados para (a) entrevistas semi-estruturadas e (b) dinâmica, onde dividiremos os participantes em grupos responsáveis por analisar um aspecto do problema e, ao final da dinâmica, consolidar os achados em uma solução única. Nesse processo buscamos desenhar uma Plataforma "ideal"do ponto de vista dos participantes. No final dos estudo, faremos novas entrevistas individuais com pessoas que não participaram do estudo inicial para validar com eles se a solução proposta é adequada. Visa-se entender quais as principais barreiras para criação e apropriação a partir das propostas de valor, e selecionar, dentre os indicadores de plataforma disponíveis, quais deles dimensionam melhor as dificuldades relatadas. Também serão analisadas as informações de telemetria da Plataforma (e.g., logs) de modo a mapear o uso da Plataforma quantitativamente.

\section{Atividades realizadas}

A pesquisa encontra-se em fase inicial de desenvolvimento. O levantamento bibliográfico preliminar sobre o tema "Impacto das plataformas digitais nos ecossistemas de negócios" permitiu a identificação de uma lacuna na literatura sobre os processos de criação a apropriação de valor em Ecossistemas de negócio. A partir disso, foram empreendidos esforços para construir um MSL sobre o tema, cujo resultado ajudou na compreensão das oportunidades de pesquisa existentes e as áreas que possibilitariam uma investigação mais aprofundada, bem como a submissão de um artigo para conferência de SI. Partindo das conclusões desse estudo, desenvolvemos o tema e as linhas guia para o estudo atual. Além disso, na construção da proposta de solução, para trazer uma base teórica à pesquisa desenvolvida, estamos analisando a teoria dos Boundary Objects e sua explicação sobre os mecanismos de dominação de um grupo sobre o outro através de objetos compartilhados. Argumenta-se que essa teoria pode ser útil para explicar como o Líder utiliza a Plataforma Digital como um Boundary Object para controlar os participantes do Ecossistema.

\section{Considerações Finais}

O projeto aborda um tema atual e relevante que coloca luz sobre lacunas existentes na literatura e indústria de maneira geral. A solução apresentada visa estender o conhecimento existente na área e contribuir tanto na validação de uma teoria, quanto criação de instrumento para aplicação prática. O projeto tem impacto na literatura, uma vez que preenche uma lacuna identificada na criação e apropriação de valor, bem como joga luz sobe as relações de poder e os mecanismos de dominação utilizados dentro das Plataformas Digitais para controlar os Ecossistemas de negócio. O projeto também fornece ferramentas que apoiam as organizações que participam de um Ecossistema de Negócios e dependem de Plataformas Digitais para acesso a recursos vitais, no processo decisório sobre como lidar com essa condição.

Em relação às ameaças do projeto, as ameaças internas estão ligadas às possíveis dificuldades de recrutar participantes da Plataforma Digital para as atividades, além da limitação de não considerar gaps em outros tipo de Plataformas. Já as ameaças externas estão ligadas à validação ser feita em uma Plataforma Digital ainda em fase inicial, com poucos usuários e que conta com um volume baixo de transações. 


\section{Referências}

de Reuver, M., Sørensen, C., and Basole, R. C. (2018). The digital platform: a research agenda. Journal of Information Technology, 33(2):124-135.

for App Fairness, C. (2021). The app store is ruled by anti-competitive policies. https://appfairness.org/issues/anti-competition/.

Hein, A., Schreieck, M., Riasanow, T., Setzke, D. S., Wiesche, M., Böhm, M., and Krcmar, H. (2019). Digital platform ecosystems. Electronic Markets, pages 1-12.

Lovejoy, B. (2021). Bypass the app store, suggests apple. https://9to5mac.com/2021/03/25/bypass-the-app-store-says-apple/.

Parker, G. G., Van Alstyne, M. W., and Choudary, S. P. (2016). Platform revolution: How networked markets are transforming the economy and how to make them work for you. WW Norton \& Company.

Peltoniemi, M. and Vuori, E. (2004). Business ecosystem as the new approach to complex adaptive business environments. In Proceedings of eBusiness research forum, volume 2, pages 267-281.

Saarikko, T. (2016). Platform provider by accident. Business \& Information Systems Engineering, 58(3):177-191.

Smartsheet (2021). Guide to gap analysis with examples. https://www.smartsheet.com/gap-analysis-method-examples.

Star, S. L. and Griesemer, J. R. (1989). Institutional ecology,translations' and boundary objects: Amateurs and professionals in berkeley's museum of vertebrate zoology, 1907-39. Social studies of science, 19(3):387-420.

Statt, N. (2021). Apple confirms cloud gaming services like xcloud and stadia violate app store guidelines. https://www.theverge.com/2020/8/6/21357771/apple-cloud-gamingmicrosoft-xcloud-google-stadia-ios-app-store-guidelines-violations. 